\title{
Vertical and Lateral Violence at Academic andProfessional Space
}

\author{
Dr. MeenaGanapathy \\ Principal, Mksssbtine, Pune.
}

\section{Introduction}

Most of us occupy two or three spaces: Academic, professional and personal spaces. These spaces are sacred to each. But at times there is encroachment of these spaces by others.People who have dependent positions are generally vulnerable to these violations. It has been well documented that nurses, Students and other health care workers are exposed to bullying, harassment and violence.(Happell, 2008). The types of violence faced are physical, non-physical, bullying, and sexual harassment. The most grievous one is physical violence. A physical assault can result in bodily injuries. Nonphysical violence could be insensitive, rude remarks to verbal abuse. (Pearson et al., 2005). Bullying is a repeated pattern of physical and / or psychological violence directed to one or more persons. Lateral or horizontal violence is perpetrated by nurses on the other nurses (Johnson, \& Rea 2009). Whereas violence like sexual harassment are committed by supervisors, coworkers, patients and their relatives or friends. Violence occurs because of the power position of the violator and the vulnerability of the nurse, \&student (victims).The sexual coercion results when two individuals of unequal status interact in a situation. When it comes to the violence on nursing students it is an iceberg because of the academic freedom, lack of firm policies and sensitive nature of the student-mentor- relationshipthe problem is difficult to define, isolate and persecute (Betts \& Newman, 1982).

Workplace violence or professional space violence toward healthcare workers in the healthcare sector has been recognized as a global problem and major public health concern The definition of this violence from the World Health Organization (WHO), which is used by researchers worldwide, includes physical violence and psychological. Physical violence refers to physical attacks resulting in physical and psychological harm, including hitting, kicking, shooting, barring, pushing, biting, and other violent acts, such as sexual harassment and rape; psychological violence is the intentional act against the person or collective force that results in physical, mental, spiritual, moral, and social damages, including insults, threats, attacks, verbal abuse, and harassment[. Krug EG, Dahlberg LL, Mercy JA, Zwi AB, Lozano R.].

Violence in the healthcare sector can normally result in adverse effects on healthcare workers, patients, and the efficiency and effectiveness of the health systems. It includes direct costs, such as illness, disability, death, lost work days, staff shortage, and loss of property; and indirect costs, such as increased occupational stress and security costs, decreased motivation and job satisfaction, reduced work performance, poor patient care quality, recruitment issues, and lower creativity

Work place violence in terms of physical violence and its repercussions were studied in detail with the large groups of samples in China \& Lebanon. This paper focuses on the physical, verbal, bullying\& lateral and vertical violence \& hostile work environment. It also discusses how students and nurses should recognize and combat and prevent it with understanding.

A study was conducted by Kai Xinget al., on Physical Violence against General Practitioners and Nurses in Chinese Township Hospitals. This study focused on the physical violence toward general physicians and nurses. A cross-sectional survey was used in a sample of 442 general practitioners and 398study only general nurses from 90 township hospitals located in Heilongiiang province, China (response rate = 84.8\%).Results: A total of 106 of the $840(12.6 \%)$ respondents reported being physically attacked in their workplace in the previous 12 months. Most perpetrators were the patients' relatives $(62.3 \%)$, followed by the patient (22.6\%); $73.6 \%$ of perpetrators were aged between 20 and 40 years. Of the physical violence incidents, about $56.6 \%(n=60)$ resulted in a physical injury, and $45.4 \%$ of respondents took two or three days of sick leave. Reporting workplace violence in hospitals to superiors or authorities was low (9.4\%). Most respondents $(62.8 \%)$ did not receive training on how to avoid workplace violence. Logistic regression analyses indicated that general nurses, aged 35 years or younger, and with a higher-level professional title were more likely to experience physical violence. Healthcare workers with direct physical contact (washing, turning, lifting) with patients had a higher risk of physical violence compared to other health care workers. A total of $62.3 \%(n=66)$ of physical assaults were conducted with knives and sticks prepared in advance or with furniture, such as tables and chairs, in the ward. Regarding consequences for the perpetrators, $50.9 \%$ of the victims chose "none" followed by a "verbal warning issued by hospital managers" (26.4\%). Procedures for reporting workplace violence were a protective factor for physical violence; when in place, reporting after psychological violence (verbal abuse, bullying/mobbing, harassment, and threats) was more protective than waiting until an instance of physical violence (beating, kicking, slapping, stabbing, etc.). 
Victims and effect of physical violence on victims: Of the 106 victims, most victims were female $(60.4 \%)$ and general nurses $(62.3 \%)$. Of the physical violence incidents, about 56.6\% $(n=60)$ resulted in a physical injury. About $62.3 \%$ of victims took time off work due to an assault; of these, $45.4 \%$ were off work for two to three days. Of those who did not report the events, the top three reasons were "it is useless" $(69.8 \%)$, "afraid of negative consequences" (58.5\%), and "felt ashamed" (41.5\%). A total of 53.8\% of victims considered these violent incidents to be preventable.

Conclusions: Physical violence in Chinese township hospitals is an occupational hazard of rural public health concern. Policies, procedures, and intervention strategies should be undertaken to manage this issue. More seriously, physical violence in the healthcare sector has begun to affect the next generation of healthcare workers in China. In 2001, according to the Chinese Medical Doctors' Association, 11\% of doctors hoped their own children would choose the medical profession in the future; this had dropped to 7\% in 2011[Chinese Medical doctor Association,2012].

A National Study on Nurses' Exposure to Occupational Violence in Lebanon: Prevalence, Consequences and Associated Factors was conducted by MohamadAlameddine, YaraMourad, and Hani Dimassi;KoustuvDalal, as Editor. A cross-sectional design was utilized to survey a nationally representative sample of 915 nurses registered with the Order of Nurses in Lebanon. Stratified random sampling by governorate was utilized. Individually-mailed questionnaires collected information on exposure to violence, degree of burnout and demographic/professional background. The main outcome variables were exposure to verbal abuse (never, 1-3, 4-9 and 10+ times) and physical violence (never, ever) over the past 12-months. Descriptive statistics were used to estimate prevalence of violence. Multivariable, binomial and multinomial regression models were carried out to investigate the correlates of exposure to verbal abuse and physical violence, respectively.

Results: Response rate was $64.8 \%$. Over the last year, prevalence of nurses' exposure to verbal abuse was $62 \%$, (CI: $58-65 \%$ ) and physical violence was $10 \%$, (CI: 8-13\%). Among respondents, $31.7 \%$ of nurses indicated (likelihood to quit their jobs and 22.3\% were undecided. Furthermore, $54.1 \%$ reported high levels of emotional exhaustion and $28.8 \%$ reported high levels of depersonalization. Compared to nurses with no exposure to verbal abuse, nurses reporting high exposure had high levels of emotional exhaustion (OR: 6.4; CI: 1.76-23.32), depersonalization (OR: 6.8; CI: 3-15) and intention to quit job (OR: 3.9; CI: 1.8-8.3). They further reported absence of anti-violence policies at their institutions (OR: 3; CI: 1.5-6.3). Nurses that were ever exposed to physical violence were more likely to be males (OR: 2.2; CI: 1.1-4.3), working day and night shifts (OR: 2.8; CI: 1.4-5.5) and subject to ten or more incidents of verbal abuse per year (OR: 46.7; CI: 10.1-214).

Conclusions: An alarming two-thirds of respondents reported exposure to verbal abuse which was found to be a significant predictor of the three subscales of burnout, intention to quit and exposure to physical violence. The prevalence of exposure to physical violence is disconcerting due to its severe consequences. Policy and decision-makers are urged to use study findings for policy and practice interventions to create safe work environments conducive to nurses' productivity and retention.

Kusui Y. et, al.,conducted a study on prevention. To investigate determinants and protective strategies for the resignation of health care workers resulting from patient-derived nuisance in medical institutions, the researchers conducted a cross-sectional survey in the 57 hospitals in Mie Prefecture, Japan. Random samplings of 775 employees (physicians, nurses, administrators, and other health care workers) were provided selfadministered questionnaires. Among 480 participants who experienced patient-derived nuisance, 132 participants considered resignation as a result, giving an estimated prevalence of $17.1 \%$ (95\% CI: $14.4 \%-19.8 \%$ ) of all respondents. Nonphysical nuisances such as "demand for an unwarranted apology" (OR: 2.57; 95\% CI: 1.61-4.12) had higher ORs for considering resignation than other kinds of nuisance. By contrast OR for the provision of human support by medical institutions was 0.49 (95\% CI: 0.28-0.86). Human support was associated with alleviation of the intention to resign.

A worldwide literature search was conducted using the CINAHL, Medline and PsycInfo data base to estimate the statistics of violence was done by paul E.S, zheqing E. zhou, XIn XC. Studies included had reported empirical results using a nursing sample, and included data on bullying, sexual harassment, and/or violence exposure rates. A total of 136 articles provided data on 151,347 nursesfrom 160 samples. The articles were identified through a database search and by consulting reference lists of review articles that were located. Relevant data were coded by the three authors. Categories depended on the availability of at least five studies. Exposure rates were coded as percentages of nurses in the sample who reported a given type of violence. Five types of violence were physical, nonphysical, bullying, sexual harassment, and combined (type of violence was not indicated). Setting, timeframe, country, and source ofviolence were coded.

Results: Overall violence exposure rates were $36.4 \%$ for physical violence, $66.9 \%$ for nonphysical violence, $39.7 \%$ for bullying, and $25 \%$ for sexual harassment, with $32.7 \%$ of nurses reporting having been physically injured in an assault. Rates of exposure varied by world region (Anglo, Asia, Europe and Middle 
East), with the highest rates for physical violence and sexual harassment in the Anglo region, and the highest rates of nonphysical violence and bullying in the Middle East. Regions also varied in the source of violence, with patients accounting for most of it in Anglo and European regions, whereas patients' families/friends were the most common source in the Middle East.

Conclusions: About a third of nurses worldwide indicated exposure to physical violence and bullying, about a third reported injury, about a quarter experienced sexual harassment, and about twothirds indicated nonphysical violence. Physical violence was most prevalent in emergency departments, geriatric, and psychiatric facilities. Physical violence and sexual harassment were most prevalent in Anglo countries;and nonphysical violence and bullying were most prevalent in the Middle East. Patients accounted for most physical violence in the Anglo region and Europe, and patient family and friends accounted for the most in the Middle East.

Definition of Lateral / Horizontal Violence: The aggressive behavior towards one nurse or group of nurses by other nurses is called horizontal or lateral violence:

Signs \& symptoms of violence:

1. Bullying

2. Acts of unkindness

3. Gossip

4. Intimidation

5. Withholding information

6. Persistent lack of respect

7. Men are overt, but women are covert with their behavior.

8. Professional terrorism under personal conflict leading to lack of respect.

9. Oppression in nursing.

Complications: Health problemCardiac diseaseStress \& anxiety, depressionWeight loss or gainIrritable Bowel Syndrome

Actions:

1. Educate - zero tolerance policy

2. Support - eradicate eliminate violence and raise awareness

3. Hold people accountable

4. Have open discussion

The following studies focused on lateral violence.Lateral violence is being harmed by your own professionals due to aggression and competition. An exploration of bullying behaviors in nursing: a review of the literature was done by Janet Lynn WilsonSenior Lecturer in Nursing, Sheffield Hallam University and Integrative Psychotherapist.

This article explored bullying behaviors in nursing in the UK and other countries, why bullying happens, and suggests actions to prevent or combat it. Bullying involves intentional and repeated psychological violence, humiliating and isolating staff from colleagues. Current literature reports that $20-25 \%$ of nursing staff experience bullying behavior. The main perpetrators are nurses in a senior position to those being bullied and colleagues who are established staff members. Those likely to be bullied are students and new staff members. Bullying can cause distress and depressions, with up to $25 \%$ of those bullied leaving their jobs or the profession, and have an impact on patient care. Factors contributing to bullying are hierarchical management and employees not feeling empowered? Silence and inaction by managers and colleagues allows this behavior to continue. A zero-tolerance policy and the addressing of this behavior clearly and promptly by managers should be instigated. Staff being bullied should not be supported by colleagues.

Castronovo, MA, Pullizzi, A\&, Evans S, did a review and proposed solutions on Nurse Bullying. Nurse bullying is an extremely common phenomenon which has detrimental consequences to nurses, patients, health care institutions, and to the nursing profession itself. It has even been linked to increased patient mortality. This article demonstrates the critical need to resolve the issue of nurse bullying. It also shows that previous attempts of resolution have not been successful, which may be partly due to the fact that the problem is relatively unacknowledged outside the nursing profession. To resolve the problem of nurse bullying, the researchers believe that the solution must include an incentive for institutions to implement the necessary interventions and to ensure that they are effective. They proposed that a measurement pertaining to the level of nurse bullying be factored into the calculation of the value-based incentive payment in the Hospital Value-Based Purchasing program. To facilitate this, they proposed that a survey be developed and implemented which is similar to the Hospital Consumer Assessment of Healthcare Providers and Systems (HCAHPS) survey. 
Gina Myers, et al., conducted a cross-hospital exploration of nurses' experiences with horizontal violence. Aim: To explore nurses' experiences of horizontal violence (HV) in three diverse non-affiliated organizations within a single city in the USA.Background: Horizontal violence, also called workplace bullying or lateral violence is a long-standing nursing issue.Method: Content analysis was used to analyze open-format textual responses from 126 registered nurses.

Results: A powerful collective story emerged from nurses' shared experiences with HV, describing the characters and the setting in which HV and its consequences exist. Nurses' depictions of HV were consistent despite the different organizational structures of their workplaces suggesting that hospital type is not the explanation for $\mathrm{HV}$, rather the culture of acute care nursing. Nurses want change and asked for tactics to resolve HV within their institutions; some provided specific solutions.Conclusion: Nurse Managers must continue to address HV by using a variety of known tactics, as well as adopting new evidence-based interventions as they are identified. The anti-bullying message should be disseminated through professional nursing organizations as well as in local health-care establishments.

Implications for nursing management: Nurse Managers need to be the culture champions who hold individuals accountable for $\mathrm{HV}$ and foster professionalism through their leadership.Ebrahimi $\mathrm{H}$,Hassankhani $\mathrm{H}$, Negarandeh R,Jeffrey C\& A, conducted a study on Violence against new graduated nurses in clinical settings: A qualitative study. Background: Ethical studies in nursing are very important topics, and it is particularly crucial with vulnerable populations such as new graduated nurses. Neglecting ethical principles and being violence toward graduates can lead to their occupational burnout, job dissatisfaction, and leaving the nursing profession.

Objective: This study was designed with the aim of understanding the experience of Iranian experienced nurses' use of lateral and horizontal violence against new graduated nurses. Research design: This qualitative study used a conventional content analysis approach; it was conducted with 18 experienced nurses. Data were collected through unstructured and semi-structured interviews of various general hospital departments in northwest of Iran and analyzed using methods as described byGraneheim and Lundman. Ethical considerations: This study was approved by the Regional Committee of Medical Research Ethics. The ethical principles of voluntary participation, anonymity, and confidentiality were considered.

Findings: "Psychological violence," "Verbal violence," "Physical violence," and "Source of violence" were four categories extracted through data analysis.Discussion: Violence behaviors are instances of workplace maltreatment that damage individual nurses, quality of care, and the ethical climate of the healthcare settings. The lateral and hierarchical violence in nursing were explained by oppressed group model.Conclusion: This study provided the context for identifying details of various types of workplace violence against new graduated nurses. It should be approached as a health system priority that requires specific multi-dimensional methods to manage consisting of identification, strategic planning, policymaking, prevention, education, and research.

Oh H, Uhm D.C\& Yoon Y.J., conducted a study on Factors affecting workplace bullying and lateral violence among clinical nurses in Korea: Descriptive study. Background\& aim:Workplace bullying and lateral violence are serious issues affecting the work life of hospital nurses. The purpose of this study was to identify the selected individual and institutional characteristics for workplace bullying and lateral violence using a conceptual framework.

Methods: A descriptive survey design was used. A convenience sample of 255 nurses in tertiary hospitals, who had a minimum of 6 months clinical experience, completed the survey. Regression analysis was used to determine factors significantly associated with workplace bullying and lateral violence. The Negative Acts Questionnaire-Revised and the Lateral Violence scale were used to measure workplace bullying and lateral violence.

Results: A negative affect, individualism and working in hospital specialty units predicted workplace bullying. Individualism, a negative affect, affiliated hospital and working hours predicted verbal abuse whereas the place of employment was significantly associated with lateral violence.

Conclusion: The results of this study identified factors that are associated with bullying and violence but did not fully support the conceptual framework. The individual characteristic negative affect was significantly associated with most types of workplace bullying and lateral violence bully whereas the place of employment was an important factor in lateral violence. Implications for nursing management: NurseManagers need to be aware that both individual and institutional factors may impact levels of workplace bullying and lateral violence in their hospitals and need to prepare specific strategies to address these multiple factors.Hsieh HF' Chen $\mathrm{YM}^{1}$, Wang HH, Chang SC\&, Ma SC, conducted a study on "Association among components of resilience and workplace violence-related depression among emergency department nurses in Taiwan: a cross-sectional study. Aim and objectives: This correlation study examined the relationship among recently workplace violence, depressive tendency, social support, and resilience of 
victimized nurses, and the researchers also tried to identify protective factors and potential targets for preventive interventions for these nurses.

Background: workplace violence in hospitals negatively affects occupational health and safety of medical professionals, especially for emergency department nurses.Design: A cross-sectional, correlation research design was applied.Methods: Hierarchical regression was used to examine data which were collected from June 2013 to December 2013 from emergency departments in Taiwan. One hundred and eighty nurses were recruited from two hospitals. Structured interviews and questionnaires were applied to collect data, including the Social Support Scale, the Resilience Scale and the Center for Epidemiologic Studies Depression.

Results: A total of $159(88.33 \%)$ nurses had suffered from physical or verbal violence by patients or their family. Resilience and peer support were significantly higher in the group without depressive tendency. Components of resilience of personal strength, social competence, (structure style and religious beliefs were significant factors which accounted for $46.0 \%$ of variance in depressive tendency. Three of the five components of resilience: personal strength, social competence and structured style were found to have profounder effects against depressive tendency than peer support.

Conclusions: Hospital managers should establish a safer working environment for emergency department nurses and reinforce their resilience against depression when they encounter workplace violence. Relevance to clinical practice: This study showed that three of the five components of resilience: personal strength, social competence and structured style are protective factors against depressive tendency in victimized nurses. Improving these three components with coping and problem-solving skills by healthcare manager would be effective measures for enhancing their resilience in situations of workplace violence.

Inherent in nursing education is the expectation that "best practices" and nursing knowledge learned in the academic environment will be translated into patient care settings with ease )and without overt resistance on the part of the existing staff. Increasingly, nurses are educated in a collaborative interprofessional environment that has the potential to build an integrated model of care where nurses would be expected, and perhaps ethically obligated, to articulate nursing science as the basis of their practice as contributing nurse members of the team. It is clear that many of the extant nursing theories address issues the opposite of the concept of lateral violence, through emphasizing respect, concerns about self-concept, caring, listening and others. All of the nursing theories focus on achieving the best theory-driven care framed in a sensitive protective person-focused framework, what Cody (2006) described as values-based practice. One of the questions to contemplate for the future of nursing and healthcare is the extent to which a stronger nursing theory base in graduate and undergraduate education would help nurses implement their unique practice once they are in care settings. The concepts that underpin the nursing discipline are soft in their focus on humanity (caring, adaptation, self-care, energy, human becoming).

It makes one speculate if nursing-theory approaches were applied broadly whether the outcome might shed some light on how to handle professional issues. Rosa (2014) reported on a hospital setting in the Midwest based on a nursing model using caring-science that demonstrated remarkable institution-wide improvements in the practice environment and specifically noted the $48 \%$ decrease in lateral violence. In this column, Dr. Susan Roberts has submitted a comprehensive review of the literature on issues related to violence and bullying over the last 30 years. Dr. Roberts SJ (2006) is a Professor and Specialty Coordinator of the Adult and Family Nurse Practitioner Programs at Northeastern University in Boston, MA. She practices as an Adult Nurse Practitioner at Harvard Vanguard Medical Associates in Wellesley, MA. Dr. Roberts has spent her career focusing on oppressed group behavior as it relates to the culture of the nursing workplace. As nurse leaders it is important to reflect on ways to succeed in the workplace so that the milieu becomes a nursing-driven caring, healthpromoting environment for those receiving healthcare, as well as nurses and other health professionals.

Lateral violence involves disruptive behaviors that lead to toxic work environments. The purpose of this project was to determine the effects of an educational intervention to increase awareness and teach cognitive rehearsal to combat lateral violence. Method: A one-time pretest-posttest evaluation design was used to evaluate the effects of a 1.5-hour educational intervention. Participants were nurses on two nursing units; 29 respondents participated in the pretest, and 25 respondents participated in the posttest. Results: Positive trends were related to the decreasing frequency of lateral violence behaviors experienced and observed after the intervention. Participants were better able to identify causes of lateral violence in their work units, suggesting the educational intervention was successful in creating a healthier work environment and decreasing the incidence of lateral violence behaviors.

Conclusion: Further evaluation is needed to determine whether the intervention would be effective over time. This project was limited by design and sample size.Bambi S, Becattini G, Pronti F, LuminiE, \&Rasero L, conducted a study on Lateral hostilities among emergency and critical care nurses. Survey in five hospitals of the Tuscany Region 
Lateral hostilities among emergency and critical care nurses. Survey in five hospitals of Tuscany. Lateral hostilities (LHs) are a kind of workplace violence. They are defined as varieties of cruel, rude, antagonistic interactions between people at the same hierarchical level. Nurses are affected by LH from 5.7\% to $65 \%$, leading to reduced work motivation, psycho-physical (disorders, and in some cases, drop out of the nursing profession.

Objective: 1.Toquantify theLHs among nurses in the emergency departments (ED) and intensive care units (ICU) in 5 hospitals of Tuscany (Italy). 2. To show the impact on the quality of their psycho-physical and professional lives.

Method: Exploratory-descriptive study, through closed-ended questionnaire.

Results: 360/444 nurses (81\%); 294 (81.6\%) were victims of LHs during the past 12 months. Gossiping, complaints shared with others without discussing with the concerned person, and sarcastic comments were the most reported LHs. LHs occur more in EDs than ICUs (respectively 90\% and 77\%; $\mathrm{p}=0.0038$ ). No statistically significant differences were observed for gender, age, or years of experience. The $17.7 \%$ of nurses asked to be moved from the ward, and $6.9 \%$ left it; $6.9 \%$ respondents had thought to leave the nursing profession; 235 (65.2\%) experienced at least one LHs related disorder during the last year. Most reported symptoms were low morale, anxiety, and sleep disturbances.

Conclusions: The incidence of LH and related disorders is high in EDs and ICUs, determining a low professional and psycho-physical quality of life.

\section{Vertical / Quid pro quo harassment / Sexual harassment:}

Quid pro quo harassment entails expressed or implied demands for sexual favors in return of some benefit or to avoid some detriment in the work place. This benefit could be promotion, pay increase etc. Detriment could be termination, demotion etc. This type of harassment is perpetrated by someone in position of power or authority over another. (This occurs when a job benefit is directly tied to an employee submitting to unwelcome sexual advances for e.g. supervisor promises an employee a raise if she will go out on a date with him or tells an employee she will be fired if she doesn't sleep with him. Only individuals with supervisory authority over a woman can engage in quid pro quo harassment since it requires the harasser to have the authority or withhold job benefits.

\section{Types of Quid pro quo harassment / Sexual harassment:}

1. Gender harassment

2. Seductive behavior

3. Sexual bribery

4. Sexual coercion

5. Sexual imposition

- Gender harassment: Insulting or degrading meaning about women. Obscene jokes about sex and women in general.

- Seductive behavior: Unwanted, in appropriate offensive sexual advances. Eg. Unsolicited sexual invitation, insistent requests for drinks or dates, phone calls or other invitations.

- Sexual coercion in animals is the use of violence, threats, harassment, and other tactics to help them forcefully copulate. Such behavior has been compared to sexual assault, including rape, among humans. Sexual coercion: It involves coercion of sexual activity or other sex-linked behavior by threat of punishment e.g., negative performance evaluation, threat of termination etc.,

- Sexual bribery: Solicitation of sexual activity or other sex linked behavior in return of reward. The preposition may be either overt or intended.

- Sexual Imposition: Gross Sexual imposition such as forceful touching, feeling, grabbing or direct sexual assault.

\section{Incidence:}

A Cornell law review article entitled " exacerbating the exasperated: Title VII liability of employers for sexual harassment reported that between 40 - 90\% of women in US workforce have been the victim of some form of sexual harassment on the job.

A ninth Circuit Judge Kozinski- states that "Every woman who has spent time in the workforce in the last 2 decades can tell at least one story about being the object of sexual harassment."

\section{Majority of incidence occurs between a supervisor \& his subordinates.}


Sakshi an NGO conducted a study in Delhi, Bangalore, Ahmedabad, Bhubaneswar \& parts of Kerala with 250 samples on sexual harassment. Their findings are as follows:

\begin{tabular}{|l|l|l|l|}
\hline Sr.No & Content of sexual harassment & Men & Women \\
\hline 1 & Heard / Encountered & 74 & 72 \\
\hline 2 & Women Victimized & 52 & 62 \\
\hline 3 & Changing lives of victim & 40 & 24 \\
\hline 4 & Sexual harassment in India & 25 & 29 \\
\hline 5 & Health, Work life after SC law & 57 & 65 \\
\hline
\end{tabular}

What to do if you are sexually harassed:

1. Every situation is unique and only you can evaluate the problem and decide upon the best possible response.

2. Family, friends, human resource professionals, women group can offer information, advice support. But ultimately it is you who can decide what is right for you.

3. Do not blame yourself for the harassment.

4. Place the onus of the blame where it belongs i.e., the harasser. Self-blame will only cause depression and will not help you or the situation.

5. Say no to the perpetrator. Be direct.

6. Tell someone; don't keep it to yourself.

Warning signs of harassment behavior of managers / coworkers:

1. Hostility between coworkers.

2. Lack of friendship amongst coworkers.

3. Complaints regarding the opposite sexes action

4. Women who act defensively / angrily towards the opposite sex.

5. Sexual intercourse with coworkers / managers.

\section{What should victims of sexual harassment do?}

Employees subjected to sexual harassment should immediately notify the supervisor. If the supervisor is the harasser, the worker should go to the supervisors' superiors. Employers cannot solve the problem if they do not know about it. If there is a grievance procedure, employee should use it. Victim should keep a written record of all incidents of harassment, detailing the place, time, persons involved and any witness. Victims can also express their disapproval of the conduct to the perpetrator and tell him or her stop.

How can employers prevent sexual harassment?

1. Develop a written policy dealing sexual harassment, indicating sexual harassment is against the law and also violates company policy.

2. Develop an effective complaint procedure for workers subjected to sexual harassment. Provide a mechanism for employers to bypass their supervisor when the supervisor participates in the harassment or fails to take proper action, the complaint procedure should encourage prompt solution to the problem.

3. Promptly and effectively respond to sexual harassment complaints. Undertake a complete and confidential investigation of any allegations of harassment and impose appropriate disciplinary actions.

4. Every Institute / Organization should constitute Vishaka Committee following Supreme Court guidelines

5. There should be zero tolerance policy regarding sexual harassment.

Effects of harassment on the victim:

Psychological reactions:

1. Insecurity, embarrassment, feelings of betrayal, confusion feeling of being powerless, sense of shame, selfconsciousness, and low self-esteem.

2. GI distress

3. Quit, self-blame, isolation

4. Sleep disturbances, nightmares

5. Sexual problems

6. Depression, anxiety, shock, denial.

\section{Career related effects:}

1. Unfavorable performance evaluations

2. Unfavorable job satisfaction

3. Loss of job or promotion 
4. Absenteeism

5. Drop in academics or work performance due to stress.

If you have encountered SH in past 12 months but took no action, what was/were the underlying reasons? Can choose more than one answer-

1. Did not think it could help

2. Not aware of the complaint channels

3. Did not want to face the situation or ruin the relationship

4. No space / time / energy to take action

5. Considered that the procedure of complaint was complicated

6. Took it as the norm of the job

7. Afraid of revenge

8. I resigned after the incidentWitness / Hearsay about SH

If you have witnessed / heard about cases of SH in your profession in the past 12 months. What action did you take? (Can choose more than one answer)

1. I mentioned the case to my colleagues / relatives

2. I encouraged the victim to take action \& offered myself as a witness.

3. I made a complaint to the related company on behalf of the victim, and offered myself as a victim.

4. I reported it to the police on behalf of the victim, and offered myself as a witness.

5. I took legal action on behalf of the action offered myself as a witness.

6. I made enquires/reported it to the EOC on behalf of the victim, and offered myself as a witness.

\section{Hostile environment:}

A single or unusually severe incident of harassment may be sufficient to create a hostile work environment particularly when the harassment is physical.

\section{What is hostile environment harassment?}

This occurs when an employee is subjected to comments of sexual nature, offensive sexual materials and unwelcome physical contact as a regular part of the work environment. Generally speaking, a single isolated incident with not be concerned hostile environment harassment unless it as extremely outrageous grievous conduct. The courts look to see whether the conduct is both serious \& frequent. Supervisors, managers, coworkers and even customers can be responsible for creating a hostile environment.

\section{How to deal with hostile environment?}

Step 1. Act immediately: Tell the individual that the behavior is unwelcome and to stop the behavior now! Step 2.Document the incident: Date, time, place of incident, specific unwelcome behavior, your response, names of witness, couples of documents e.g., notes, e-mails, pictures etc.

Step 3.Report the behavior immediately to your supervision or the agency officially designated to receive complaints.

Step 4.Report the behavior specific when reporting unwanted behavior: who, what, where, when, why? How many times has this happened?

Any witnesses?

What were your feelings?

Was your work affected?

Did you document the incident?

What remedy do you want?

Step 5: Report retaliation: If you believe that you are the subject of retaliation, immediately report takes to your supervisor and to appropriate agency official.

\section{Strategies of prevention:}

1. Know and follow the organizations / government policy prohibiting harassment.

2. Act professionally, treat coworkers with respect.

Asan employer ask yourself:

1. Could your behavior offend or hurt people at work place?

2. Could your behavior be interpreted by another as harassment?

3. Would you like your behavior to be discussed by others?

4. Would you like your friends, partners, children or sibling to be treated in same manner? 


\section{Role of employer:}

1. Do not disbelieve the victim

2. Encourage\& support

3. Be professional at all times

4. Avoid making assumptions

5. Think before making personal comments

6. Be supportive of people who wish to talk about being harassed.

7. Direct them to appropriate persons / authorities.

\section{Role of victim:}

1. Speak out

2. Keep records tell someone create a witness to the behavior.

3. Set your own boundaries.

4. Be aware of situations and people who may harm you.

5. Trust your own instincts about possible danger

6. Get a medical check up

7. Report to appropriate person in the organization.

\section{Role of organization:}

1. Sexual harassment policy

2. Awareness training

3. Enforcement of policy

4. Complaints committees / Vishaka committee

\section{Points to ponder:}

1. Harassment is now becoming an acceptable behavior.

2. Victims do not voice out due to fear, shame \&rejection

3. Respect for human being is deteriorating.

4. Fight against "wrong is right."

Interventions such as sensitization, capacity building on coping strategy skills, legislation and policy reviews are needed to address these concerns.Have you encountered the following miscommunication harassment in your profession in past 12 months (can choose more than one answer).

1. Age discrimination i.e., treating people less favorably on the basis of age.

2. Miscommunication against new recruits

3. Sex discommendation (e.g.), new recruits (Promote employees of a particular sex).

4. Family status discrimination (e.g.) woman is transferred to a less favorable job after child birth because employer thinks that a woman with an infant will not be able to travel.

5. Racial discrimination (Treating people favorably on the basics of their race)

6. Racial harassment (e.g. engaging in name calling, which people of certain racial groups may find offensive or improper.

7. Marital status discrimination (e.g. prefers to employ singles / married).

8. Pregnancy discrimination (treating women less favorably because of her pregnancy)

9. Disability discrimination (treating women less favorably because of her pregnancy)

10. Disability harassment (e.g. name calling mimicking gestures of people indicating)

11. Racial vilification (e.g. an activity in public incites hatred, serious contempt for or sense indicate of a person because of his/her race.

12. Disability vilification

13. Sexual orientation discrimination (treating people less favorably on the basis of this sexual orientation.)

\section{A poem from the unabridged devil's dictionary}

Ambition:

Once a discontented frog said"I will be a frog no more-Call me a bird" But still in flyingHe would alight, despite his trying,Quite as quickly as before.Still his toes were joined by leathers.I am a duck said he; but feathers, on his body,Cold and podgy,Sprouted not to coat him o'er;and his head was still a frog's head.

- David Alexander Hogshead. 


\section{Conclusion}

Nursing is suffering. Often doctors view them not as equals, but as helpers. Their knowledge and skills are highly over looked. Another problem facing nursing is their own selves. Too many of them are unfriendly and unwilling to assist one another that they make their jobs even less pleasant

\section{Summary}

From the above studies and articles we can infer that violence is inherent in human beings. The uneven power structure of the world contributes to harassing the subordinates and socially challenged people. We need to educate, organize and retaliate on this occurrence of harassment. We should not be mute victims and witnesses.

\section{Reference}

[1]. Happell, B. (2008). In search of a positive clinical experience. Mental Health Practice, 11(9), 26 - 31.

[2]. Pearson, et.al.www.informath.org/ apprise/a4128/b1206.pdf

[3]. Johnson SL, Rea RE. Workplace Bullying: Concerns for Nurse Leaders. Journal of Nursing Administration, 2009.

[4]. Betts N.D., Newman, G.C (1982) defining the issue: Sexual harassment in college and university life. Contemporary Education, 54, $48-52$.

[5]. World Health Organization. World Health statistics 2010: World Health Organization.

[6]. Krug, E. G, Dahlberg, L.L, Mercy, J.A., Zwi, A.B, Lozano,R. World report on violenceand health Geneva, Switzerland: World Health Organization, 2002

[7]. Kai Xing, et al., Physical violence against General Practitioners and Nurses in Chinese Township Hospitals: A Cross Sectional Survey, PLos one.2015; 10 (11):e0142954. Published online2015 Nov 16. DOI 10.1371 / journal. Pone 0142954.

[8]. Chinese Medical Doctor Association. Fourth Chinese physician practice status of research reports 2011.http://www.cmda.gov.cn/gongzuodongtai/zhinengbumen/2011-08-08/9778.html (accessed May 8, 2012).

[9]. Mohammad A, Yara, M, \& Hani, D, KostuvDalal Editor. A National Study on Nurses' Exposure to Occupational Violence in Lebanon: Prevalence, Consequences and associated Factors. PLos one. 2015 Sep 10. DOI 10.1371/ Journal pone.0137105. PMC ID: C 4565636.

[10]. Kusui Y, Yamazaki T., Yamada T.et.al., Workers Resignation due to patient nuisance in hospitals: Determinants and Prevention. Arch Environ. Occup Health 2016 Jan 19:1 - 10 (E pub ahead print). PMID: 26786616. DOI: 10.1080/ 19338244.2016.1140628.

[11]. Paul E.S.,zhiqing E, Zhou \&Xin XC 'Nurse exposure to physical and non-physical violence, bullying and sexual harassment: A quantitative review, International Journal of Nursing studies 51 (2014) 72-84. www.elsevier.com/uns.

[12]. Janet L. W. An Exploration of Bullying Behaviors in Nursing: A Review of Literature. DOI: http:// dx.doi.org/10.12968/bjon.2016.25.6.303.

[13]. Hsieh H. F, Chen Y.M, Wang H.H, Chang S,C, \& Ma S.C. Association among Components of Resilience and Workplace ViolenceRelated Depression Among emergency Department nurses in Taiwan: A Cross Sectional Study. J. Clin. Nurs.2016 June 23. Doi: 10.1111/jocn.13309. (Epub ahead of print).

[14]. Gina M, Denise C- A, Priscilla W,et.al., A Cross Hospital exploration of nurses' Experience with horizontal Violence.DOI:10.1111/ jonm.12365.

[15]. Ebrahimi H, Hassankhani h, Negarandeh R. Jeffrey C, \&Azizi A, Violence against New graduated Nurses in Clinical Settings: A Qualitative Study. Nurs Ethics. 2016 Jan 24.Pii 0969733015624486. (Epub ahead of print).

[16]. Castronovo M.A, Pullizzi A, \& Evans S. Nurse Bullying: A review and a proposed solution. Nurs outlook. 2016, May - June;64 (3)208 - 14 doi:10.1016/J.outlook. 2015.11.008, Epub 2015, Nov 22. PMID: 26732552.

[17]. Oh H, Uhm D.C\& Yoon Y.J., Factors affecting workplace bullying and latersl violence among clinical nurses in Korea: a descriptive study. John Wiley \& Sons ltd. 2015. PMID: 261272343. DOI: 10.1111/ jonm.12324.

[18]. Brooks, Rosa Ehrenreich (1999). "Dignity and discrimination: toward a pluralistic understanding of workplace harassment". Georgetown Law Journal. Georgetown University Law Center. 88 (1): 14-20. Pdf.

[19]. Cody W.K. (2006) Value - based practice and evidence - based care. Nursing Science Quartely,7 (4) 144 - 145.

[20]. Robert S. J,(1997) Nurse Executives in the 1990s. Empowered or Oppressed? Nursing Administration Quartely, $22(1), 64$ - 71.

[21]. Bambi S, Becattini G, Pronti F, Lumini E, \&Rasero L. Lateral hostilities among emergency and critical care nurses.: Survey in five hospitals of Tuscany region. PIMD: 24441466 Doi: 10.1702/1381.15359.

[22]. David B.O, Exacerbating the Exasperating: Title Vll Liability of Employers for Sexual Harassment Comitted by Their Supervisors. Cornell Law Review, Vol 81. Issue 1, November,1995, Article 3.

[23]. Scott Glover (2008-06-11). "9th Circuit's chief judge posted sexually explicit matter on his website". Los Angeles Times.

[24]. Associated Press (June 13, 2008). California: Judge Calls for Inquiry Into His Conduct Over Web Site.

[25]. Mala R, Sankara S,P, Sukanya R, Sarita P.V. : Sexual harassment in the work place: Lessons from a web - based survey. Online ISSN:0975- 5691. Print ISSN 0974- 8466. Vol 2, No 2 (2005).

[26]. Bierce, Ambrose \& Hopkins, Ernest Jerome (1989). The Enlarged Devil's Dictionary: With 851 newly discovered words and definitions added to the previous thousand-word collection. London: Penguin Books.

[27]. International labor organization and forum for women law and development sexual harassment of work place in Nepal. Kath Mandu; International labor office, 2004. Available from: http://www.i/o.kathmandu/documents/publications wcms-113 780. Pdf

[28]. Chinese Medical Doctor Association. Fourth Chinese physician practice status of research reports 2011.http://www.cmda.gov.cn/gongzuodongtai/zhinengbumen/2011-08-08/9778.html (accessed May 8, 2012). 